\title{
DETECCIÓN DE Cercospora stizolobii EN CULTIVOS DE Stizolobium aterrimum EN QUEVEDO, ECUADOR
}

\author{
DETECTION OF Cercospora stizolobii IN Stizolobium aterrimum CULTURES AT \\ QUEVEDO, ECUADOR
}

\author{
${ }^{\bullet}$ Felipe Rafael Garcés Fiallos ${ }^{1,2}$, Washington Fernando Mora Silva ${ }^{1}$ \\ ${ }^{1}$ Unidad de Investigación Científica y Tecnológica, Universidad Técnica Estatal de Quevedo, $\mathrm{km} 7$ \\ vía Quevedo - El Empalme, C. P. 73. Mocache,Los Ríos,Ecuador. ${ }^{\circ}$ felipegarces23@yahoo.com.ec \\ ${ }^{2}$ Facultad de Ciencias Agrarias, Universidad Técnica Estatal de Quevedo. Campus Ing. Manuel Haz Álvarez, \\ km 1 11/2 vía a Santo Domingo de los Tsáchilas, C. P. 73. Quevedo, Los Ríos, Ecuador.
}

\begin{abstract}
RESUMeN
$\mathrm{L}^{2}$ mucuna negra (Stizolobium aterrimum Piper \& Tracy) es una planta forrajera anual, perteneciente a la Familia Fabaceae, utilizada para la alimentación de ganado bovino, porcino y caprino en el Ecuador. En las fincas "La María" y "La Represa" pertenecientes a la Universidad Técnica Estatal de Quevedo (UTEQ), se encontraron lesiones (manchas cafésrojizas circulares con halo más oscuro) en trifolios de $S$. aterrimum. Posteriormente esos trifolios fueron llevados al Laboratorio de Microbiología Ambiental y Vegetal, UTEQ, realizándose observaciones macro y microscópicas para determinar el agente causal de esta sintomatología. También se realizaron aislamientos del tejido con presencia de lesiones, sembrándolo en medio de cultivo (PDA). Bajo lupa estereoscópica se identificaron estructuras de carácter fúngico correspondientes a esporodoquios, los que sobresalen de la superficie de los trifolios de $S$. aterrimum. De las estructuras se obtuvieron conidias de diferentes longitudes, delgadas, multicelulares y oscuras, midiendo entre 4-7 $\mu \mathrm{m}$ de ancho y 43-140 $\mu \mathrm{m}$ de largo. El organismo no se desarrolló en medio de cultivo en los aislamientos realizados. Por las características morfológicas presentadas, el organismo corresponde a un hongo de carácter patogénico denominado Cercospora stizolobii, lo cual correspondería al primer reporte en el Ecuador asociado a $S$. aterrimum. De esta forma, se deberá trabajar en un mejor manejo sanitario en la producción de plantas de $S$. aterrimum, para reducir potenciales daños y el poder convivir con esta enfermedad.
\end{abstract}

Palabras clave: Mucuna negra, lesiones foliares, cercosporiosis.

Recibido: 5-Octubre-2011. Recibido en forma corregida: 7-Noviembre-2011 Aceptado: 9-Junio-2012.

Publicado como NOTA TÉCNICA en Ciencia y Tecnología 5(1): 25-28. 2012

\begin{abstract}
$\mathrm{T}$ he black mucuna (Stizolobium aterrimum Piper \& Tracy) is an annual forage plant,which belongs to the Fabaceae family, it is used to feed cattle, pigs and goats in Ecuador. Lesions were found (reddishbrown circular spots with darker halo ) on trefoils of $S$. aterrimum located in the experimental farms "La María" and "La Represa" belonging to Quevedo Technical State University (UTEQ) later those trefoils were carried out to the Microbiology Plant and Environmental laboratory, UTEQ, where carried out macro and microscopic observations to determinate the causal agent for this symptomatology. Also it was carried out isolation of the tissue with presence of lesions, it was sown like resource of culture (PDA). They were identified using stereoscopic magnifying glass, structures with fungal character corresponding to sporodochia which excel from the surface of the trefoils of $S$. aterrimum. In the structures were obtained conidia in differents lengths, thin, multicellular, dark, measuring between 4-7 $\mu \mathrm{m}$ in width and $43-140 \mu \mathrm{m}$ in length. The organism did not develop in the middle of culture in isolations that were carried out. By the morphological features presented, the organism corresponds to a fungus with pathogenic character called Cercospora stizolobii, which would correspond to the first report in Ecuador, associated with S. aterrimum. Thereby, it must work in a better health management in the production of S. aterrimum plants to diminish potential damage and to live with this disease.
\end{abstract}

Key words: Mucuna black, leaf spot, foliar injury. 


\section{INTRODUCCIÓN}

$\mathrm{L}$ a mucuna negra (Stizolobium aterrimum) o fréjol terciopelo es una planta forrajera anual, perteneciente a la Familia Fabaceae, utilizada para la alimentación de ganado bovino, porcino y caprino en muchos países, entre ellos el Ecuador. Esta leguminosa también es usada en asociaciones de cultivos con maíz (Kamel, 2002; González y Díaz, 2008; Díaz et. al., 2004) y como abono verde en suelos arenosos pobres (García, 2001). Por otro lado, esta planta forrajera es empleada como controladora de nemátodos fitopatógenos (Moraes, 2006; Bringel y Silva, 2000; Andrade y Ponte, 1999).

Dentro de las limitantes de la siembra o establecimiento de esta leguminosa, es el ataque de enfermedades que ocasionan daños y pérdidas. Existe poca información a nivel nacional o internacional sobre la ocurrencia y ataque de enfermedades a $S$. aterrimum, encontrando solamente antracnosis (Solórzano, 2002), Macrophomina phaseolina (Berner et al., 1992) y cercosporiosis causada por Cercospora stizolobii (Finch y Finch, 1997; Viégas, 1945; Rangaswami \& Mahadevan, 2006), no existiendo reporte de la ocurrencia en mucuna negra ( $S$. aterrimum) en el Ecuador.

Este organismo anamorfo Hyphomycete (Kendrick, 1992), pertenece a la Subclase Hyphomycetidae, al Orden Moniliales, Familia Dematiaceae, género Cercospora (Alexopoulus et al. 1996). El género Cercospora puede causar el ahogamiento y muerte de plántulas (Agrios, 2004), así como manchas foliares (Barnett y Hunter, 2003). Así mismo, Menezes y Oliveira (1993) relatan que este patógeno produce principalmente síntomas foliares; los conidióforos crecen agrupados y sobresalen de la superficie de la planta a través de los estomas y los conidios son hialinos y oscuros, de formas largas, filiformes, y multicelulares.

\section{Materiales y MÉtodos}

$\mathrm{E}$ n septiembre de 2010 se colectaron muestras foliares de plantas de $S$. aterrimum (mucuna negra) en la finca experimental La María perteneciente a la Universidad Técnica Estatal de Quevedo (UTEQ), de coordenadas geográficas $79^{\circ} 30^{\prime} 08^{\prime \prime}$ Longitud Este y $01^{\circ} 00^{\prime} 35^{\prime \prime}$ Latitud Sur, y de altitud 74 metros sobre el nivel del mar. La temperatura media de la zona es de $27.09^{\circ} \mathrm{C}$, precipitación media anual de 2,018.17 mm y humedad relativa de $94.09 \%$. También se colectaron muestras foliares de Mucuna en la finca La Represa (UTEQ), de coordenadas geográficas 79 30' 23'" Longitud Este y $01^{\circ} 00^{\prime} 32^{\prime \prime}$ Latitud Sur, ubicada en el Recinto Faita km 7.5 vía Quevedo - Babahoyo, a una altitud de 85 metros sobre el nivel del mar. La temperatura media es de $25.4^{\circ} \mathrm{C}$, precipitación media anual de $1,609.3 \mathrm{~mm}$ y humedad relativa de $82 \%$.

Las muestras fueron llevadas al Laboratorio de Microbiología Ambiental y Vegetal de la UTEQ, donde se realizaron observaciones macro y microscópicas de las lesiones de los foliolos asociadas a la sintomatología foliar y analizando y midiendo estructuras del organismo asociado a las lesiones de las hojas. Los cultivos de tejido con presencia de lesiones, fueron sembrados en medio de cultivo (Papa Dextrosa Agar) conforme la metodología descrita por Viégas (1945), utilizando para ello ocho discos Petri de vidrio, dejándolas en estufa de cultivo por 12 días a $25 \pm 2^{\circ} \mathrm{C}$, con la finalidad de detectar organismos asociados a las lesiones foliares. Esta actividad se la realizó por dos ocasiones.

Los conidios del patógeno fueron medidos (largo y ancho) en el Laboratorio de Micología y Fitopatológica de la Facultad de Agronomía y Medicina Veterinaria de la Universidad de Passo Fundo, Río Grande del Sur, Brasil.

\section{Resultados Y DISCUSIÓN}

$\mathrm{E}^{\mathrm{n}}$ n los análisis y observaciones se observó que la sintomatología corresponde a manchas cafés-rojizas circulares con halos más oscuros en los bordes (Figura 1), sobre éstas se desarrollan estructuras de carácter fúngico correspondientes a conidióforos agrupados que corresponden a esporodoquios que sobresalen de la superficie de los trifolios (Figura 2A).

Las conidias presentan formas delgadas, multicelulares y de base obtrocónica, midiendo entre 4-7 $\mu \mathrm{m}$ de ancho y 43-140 $\mu \mathrm{m}$ de largo. Estas características encontradas son similares con las de Viégas (1945), quienes mencionan rangos de 4-5 $\mu \mathrm{m}$ de ancho y 40-60 $\mu \mathrm{m}$ de largo.

Al cabo de los 30 días de haber realizado en las dos ocasiones, el aislamiento del patógeno, no se constató ningún crecimiento de $C$. stizolobii en los discos Petri. La no obtención de cultivos de C. stizolobii en los aislamientos desde trifolios de $S$. aterrimum, requiere de mayor investigación en los protocolos de aislamiento.

Al constatar este nuevo patógeno en el país, se deberá realizar un mejor manejo de plantas de mucuna negra, siendo una recomendación la selección genética (genotipos tolerantes o resistentes a la enfermedad), así como el uso de fungicidas en semillas y parte aérea, y la rotación de este cultivo, evitando así la fuente de inóculo primario de la enfermedad. En relación a la aplicación de fungicidas, Carmona et al. (2011) mencionan que en el cultivo de soya, con la aplicación de azoxistrobina en mezclas con triazoles, así como la 


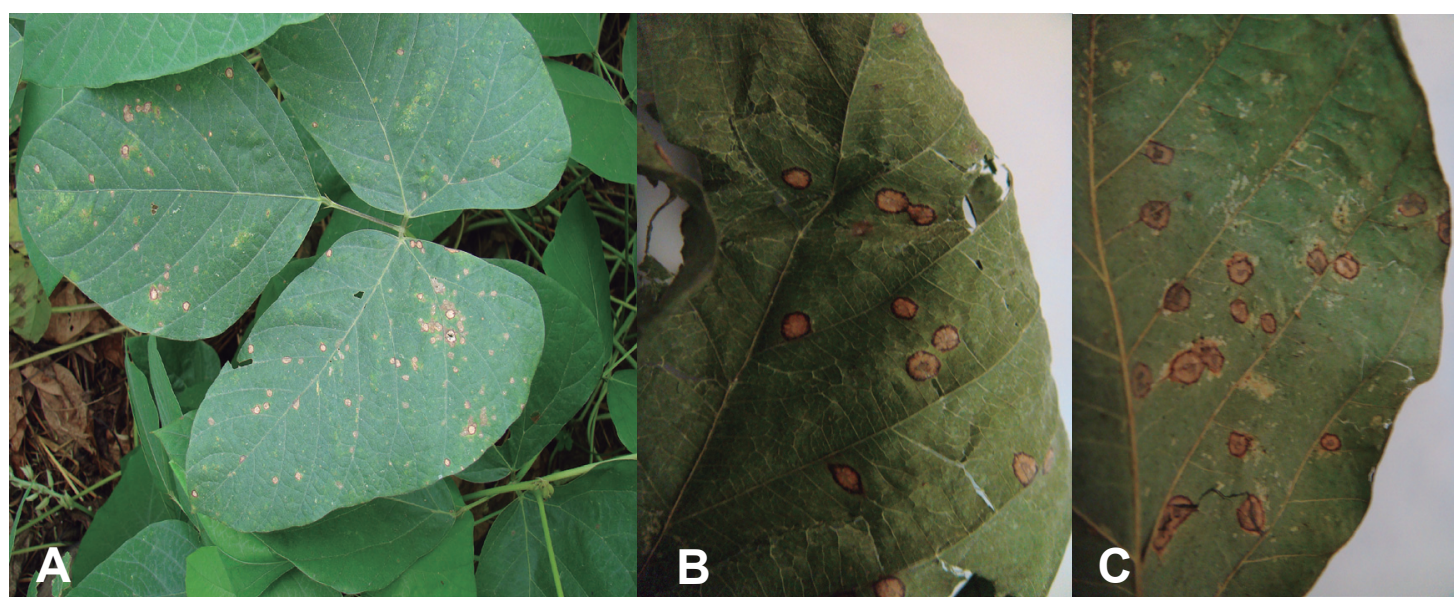

Figura 1. Síntomas (manchas cafés-rojizas circulares con halo mas oscuro) de Cercospora stizolobii en trifolios (A), el haz (B) y en el envés (C) de folíolos de Stizolobium aterrimum.

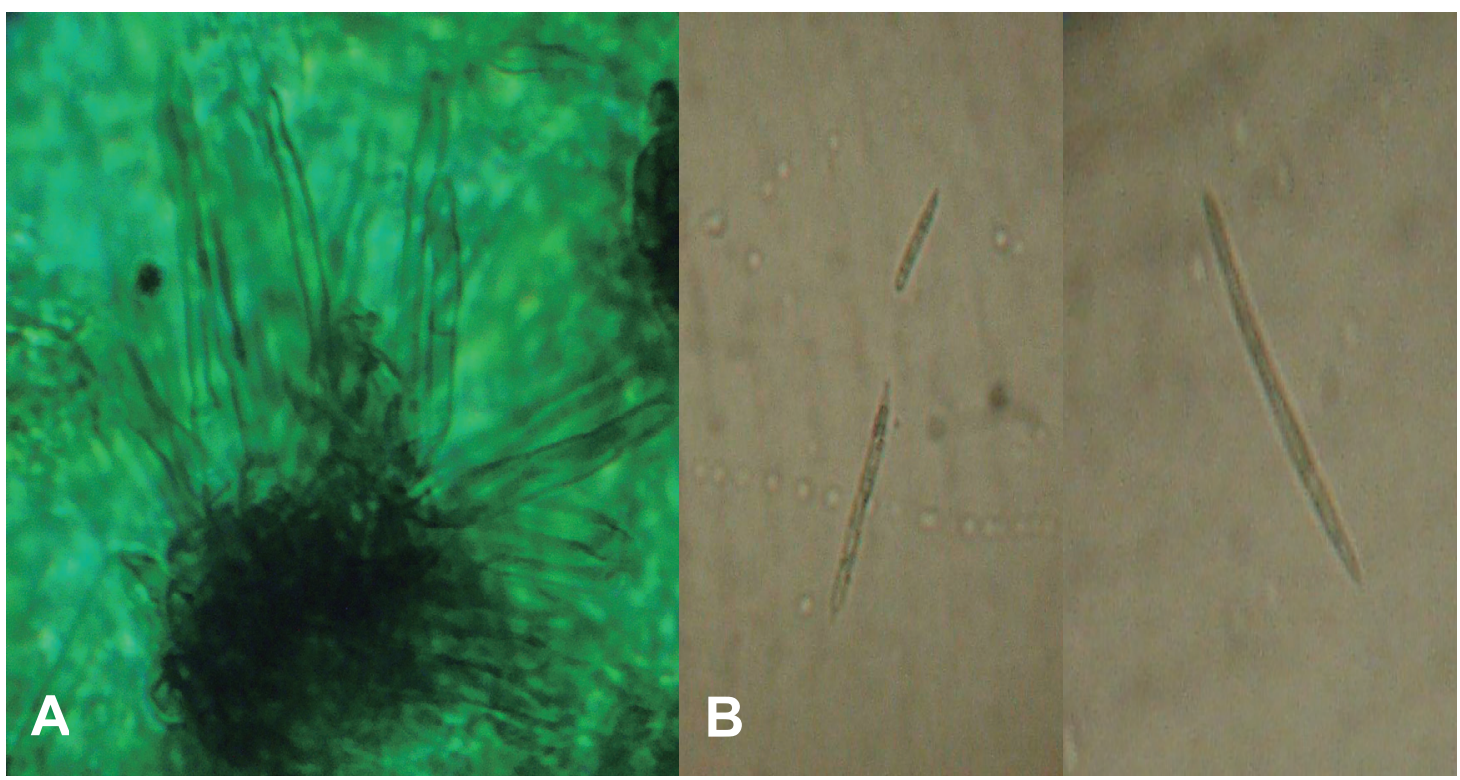

Figura 2. Esporodoquio (A) y conidias (B) de Cercospora stizolobii (Bars $=10 \mu \mathrm{m})$.

mezcla de los triazoles evaluados en cuatro ensayos, controló las enfermedades finales de ciclo (EFC), incluida la cercosporiosis (Cercospora kikuchii T. Matsu \& Tomoyasu). Los mismos autores relatan que además, el tratamiento de semillas con fungicidas es una medida eficiente y complementaria, principalmente en aquellos lotes donde aún no se han observado síntomas de las enfermedades, o en zonas nuevas de cultivo.

\section{Conclusiones}

T a presencia de la sintomatología foliar en plantas $\mathcal{L}$ de $S$. aterrimum es el primer reporte realizado en el Ecuador continental.

La no obtención de cultivos de C. stizolobii en los aislamientos desde trifolios de $S$. aterrimum, requiere de mayor investigación en los protocolos de aislamiento. Como la identificación de $C$. stizolobii fue de carácter morfológico, sería recomendable corroborar por medio de biología molecular, y la vez determinar variabilidad poblacional de este patógeno a nivel geográfico (posibles cepas con diferentes grados de virulencia).

\section{Agradecimiento}

Al Laboratorio de Micología Fitopatológica de la Facultad de Agronomía y Medicina Veterinaria de la Universidad de Passo Fundo, Río Grande del Sur, Brasil, por haber facilitado sus instalaciones para la medición del patógeno en estudio. 


\section{LITERATURA CITADA}

Agrios, G. N. 2004. Fitopatología. Segunda edición. Limusa. México. 838 p.

Alexopoulos, G. J., C. W. Mims, M. Blackwell. 1996. Introductory Mycology. $4^{\circ}$ Edition. John \& Sons, Inc. New York. 869 p.

Andrade, N. C. e J. J. Ponte, 1999. Efeito do sistema de plantio em camalhões e do consórcio com Crotalaria spectabilis no controle de Meloidogyne incognita em quiabeiro. Nematologia Brasileira 23:11-16.

Barnett, H. L. and B. B. Hunter. 2003. Ilustrated genera of imperfect fungi. Fourth edition. American Plant Phytopathological Society, St. Paul. 218 p.

Berner, D. K., A. S. Killani, E. Aigbokhan and D. C. Couper. 1992. Macrophomina phaseolina on the tropical cover Mucuna pruriens var. utilis. Plant Disease 76:1283.

Bringel, J. M. M. and G. S. Silva. 2000. Efeito antagônico de algumas espécies de plantas a Helicotylenchus multicinctus. Nematologia Brasileira 24:179-181.

Carmona, M., M. Gally, F. Sautua, A. Abello e P. Lopez. 2011. Uso de mezclas de azoxistrobina y triazoles para controlar enfermedades de fin de ciclo de la soja. Summa Phytopathologica 37(2):134-139.

Diaz, G., K. Estupiñán, V. Mite, F. P. Amores, H. G. Mera. 2004. Evaluación de la mucuna, urea, roca fosfórica y zeolita para el incremento de la producción y fertilidad del suelo de pequeños productores de maíz. Programa de Modernización de los Servicios Agropecuarios, Quevedo, EC. (Boletín técnico $\left.\mathrm{n}^{\circ} 10\right) .20 \mathrm{p}$.

Finch, H. C. y A. N. Finch. 1997. Los hongos comunes que atacan cultivos en América Latina. Trillas, México, D.F. 188 p.

García, L. F. 2002. Introdução e avaliação de leguminosas para adubação verde em solos arenosos de tabuleiros costeiros do Piauí. Revista Facultad de Agronomía 28:93-103.
González, B. O. y G. C. Diaz. 2008. Análisis económico y producción del maíz (Zea mays L.) asociado con mucuna (Stizolobium aterrimum) en siembra directa y dos sistemas de fertilización nitrogenada. Ciencia y Tecnología 1:37-41.

Kamel, T. O., G. J. Carvalho e R. N. M. Souza. 2002. Plantas de cobertura e seus efeitos sobre o feijoeiro em plantio direto. Pesquisa Agropecuária Brasileira 37(8):1079-1087.

Kendrick, B. 1992. The Fifth Kingdom. Second edition. Focus Text, Waterloo. $406 \mathrm{p}$.

Menezes, M. e S. M. A. Oliveira. 1993. Fungos Fitopatogênicos. Imprensa Universitária da UFRPE. Recife. 277 p.

Moraes, S.R.G., V. P. Campos, E. A. Pozza, A. Fontanetti, G. J. Carvalho e C. Maximiniano. 2006. Influência de leguminosas no controle de fitonematóides em cultivo orgânico de alface americana e repolho. Fitopatologia Brasileira 31:188-191.

Rangaswami, G. and A. Mahadevan. 2006. Diseases of Crop Plants in India. Fourth edition. Connaught Circus. New Delhi. 548 p.

Solórzano J. A. 2002. Evaluación agronómica de seis genotipos de mucuna (Stizolobium spp). Trabajo presentado en el I Congreso Nacional de Agricultura Conservacionista. San José, CR. (en línea). Consultado 14 ene 2011. Disponible en http://www.mag.go.cr/bibliotecavirtual/f088080_089.pdf

Viégas, A. P. 1945. Alguns Fungos do Brasil: Cercosporae. Vol. 8. $\mathrm{n}^{\circ}$. 1. Boletim da Sociedade Brasileira de Agronomia. Rio de Janeiro. 160 p. 